\title{
Molecular and Chemical Analysis of the Lipopolysaccharide from Aeromonas hydrophila Strain AH-1 (Serotype 011)
}

\author{
Susana Merino ${ }^{1}$, Rocío Canals ${ }^{2}$, Yuriy A. Knirel ${ }^{3}$ and Juan M. Tomás ${ }^{1, *}$ \\ 1 Department of Microbiology, Faculty of Biology, University of Barcelona, Diagonal 643, \\ 08071 Barcelona, Spain; E-Mail: smerino@ub.edu \\ 2 Institute of Integrative Biology, University of Liverpool, Crown Street, L69 7ZB Liverpool, UK; \\ E-Mail: rcanals@gmail.com \\ 3 N.D. Zelinsky Institute of Organic Chemistry, Russian Academy of Sciences, Moscow V-334, \\ Russia; E-Mail: yknirel@gmail.com \\ * Author to whom correspondence should be addressed; E-Mail: jtomas @ub.edu; \\ Tel.: +34-93-4021486; Fax: +34-93-4039047.
}

Academic Editor: Antonio Molinaro

Received: 27 February 2015 / Accepted: 7 April 2015 / Published: 14 April 2015

\begin{abstract}
A group of virulent Aeromonas hydrophila, A. sobria, and A. veronii biovar sobria strains isolated from humans and fish have been described; these strains classified to serotype $\mathrm{O} 11$ are serologically related by their lipopolysaccharide (LPS) $O$-antigen $(O$-polysaccharide), and the presence of an S-layer consisting of multiple copies of a crystalline surface array protein with a molecular weight of $52 \mathrm{kDa}$ in the form of a crystalline surface array which lies peripheral to the cell wall. A. hydrophila strain AH-1 is one of them. We isolated the LPS from this strain and determined the structure of the $O$-polysaccharide, which was similar to that previously described for another strain of serotype O11. The genetics of the O11-antigen showed the genes (wbo11 cluster) in two sections separated by genes involved in biosynthesis and assembly of the S-layer. The O11-antigen LPS is an example of an ABC-2-transporter-dependent pathway for $O$-antigen heteropolysaccharide (disaccharide) assembly. The genes involved in the biosynthesis of the LPS core (waao11 cluster) were also identified in three different chromosome regions being nearly identical to the ones described for A. hydrophila AH-3 (serotype O34). The genetic data and preliminary chemical analysis indicated that the LPS core for strain AH-1 is identical to the one for strain AH-3.
\end{abstract}


Keywords: Aeromonas; genomics; proteomics; lipopolysaccharide; O11-antigen; LPS-core

\section{Introduction}

Lipopolysaccharides (LPS) are amphiphilic macromolecules generally comprised of three defined regions distinguished by their genetics, structures, and function: the lipid $\mathrm{A}$, the core oligosaccharide (OS) and a polysaccharide portion, $O$-antigen. While the structures of lipid A and core oligosaccharide are highly conserved among bacterial genera, the $O$-polysaccharide varies in common bacterial species [1]. In many bacteria, the $O$-antigen variations give the biological identity at an intraspecific level (serogroups, serotypes or serovars) [1]. The taxonomy of the genus Aeromonas is complex due to the continuous description of novel species and the rearrangement of strains and species described so far [2]. Based on 16S rRNA and 5S rRNA gene sequence comparisons, and rRNA-DNA hybridization data, Colwell et al. (1986) [3] proposed the creation of the family Aeromonadaceae including Aeromonas as its type and unique genus. In the current edition of Bergey's Manual of Systematic Bacteriology, three genera (Aeromonas, Oceanimonas and Tolumonas) are listed in this family, although two more genera have been described recently, Oceanisphaera [4] and Zobellella [5].

In the latest edition of Bergey's Manual of Systematic Bacteriology [6], 14 phenospecies that correspond to 17 genomospecies (DNA hybridization groups or HGs) were included within the genus Aeromonas: A. hydrophila (HG1), A. bestiarum (HG2), A. salmonicida (HG3), A. caviae (HG4), A. media (HG5), A. eucrenophila (HG6), A. sobria (HG7), A. veronii (bv. Sobria, HG8, and bv. Veronii, HG10), A. jandaei (HG9), A. schubertii (HG12), A. trota (HG14), A. allosaccharophila (HG15), A. encheleia (HG16), and A. popoffii (HG17). In recent years, 11 new species have been described; therefore, 26 species have been described in the genus Aeomonas until now.

The Aeromonas genus includes a total of 97 serotypes, serotyped from reference strains of A. hydrophila, A. caviae and A. sobria [7,8], although some of these strains could be misidentified because of the increasing complexity in the identification of Aeromonas strains at the species level [9]. However, only some of them such as O3, O6, O11, O14, O16, O18, O21, O29, O33, O34 and O41 seem to be associated with virulence for specific fish species [10] and more than $60 \%$ of the septicemia cases are related to four of these serotypes: (O11, O16, O18 and O34) [11]. Serotype O11 is associated with severe infections in humans, like septicemia, meningitis and peritonitis while serotype O34, the most common in mesophilic Aeromonas, is associated with wound infections in humans and outbreaks of septicemia in fishes [12].

A group of virulent Aeromonas hydrophila, A. sobria, and A. veronii biovar sobria strains isolated from humans and fish have been described; these strains are serologically related by their $O$-antigens (serotype O11), and the presence of an S-layer consisting of multiple copies of a protein (VapA) with a molecular weight of $52,000 \mathrm{Da}$ in the form of a crystalline surface array peripheral to the cell wall A. hydrophila strain AH-1 is one of them [13]. We studied the functional genetics of the LPS-core OS and $O$-antigen of LPS from this strain, being the chemical structure of this last one similar to the one described for another strain of serotype O11 [14]. Furthermore, we found genes codifying for the production and export/assembly of the S-layer characteristic from strain $\mathrm{AH}-1$, between the biosynthetic 
genes for O11-antigen LPS production. Genetics of the AH-1 LPS-core was also studied showing the genes involved in its biosynthesis three different chromosome regions as the ones described for A. hydrophila AH-3 (serotype O34) [15].

\section{Results}

\subsection{Chemical Structure of the A. Hydrophila AH-1 O11-Polysaccharide}

The $O$-polysaccharide was obtained by mild acid degradation of the LPS isolated from bacterial cells by the Westphal procedure [16]. Sugar analysis by GLC of the acetylated alditols and (S)-octyl glycosides derived after full acid hydrolysis of the polysaccharide revealed L-rhamnose (L-Rha) and 2-acetamido-2-deoxy-D-glucose (D-GlcNAc). The ${ }^{1} \mathrm{H}-\mathrm{NMR}$ (Figure 1, bottom) and ${ }^{13} \mathrm{C}-\mathrm{NMR}$ (Figure 2, bottom) spectra of the polysaccharides showed structural heterogeneity, most likely, owing to non-stoichiometric $O$-acetylation (there were signals for $O$-acetyl groups at $\delta_{\mathrm{c}} 2.15$ and $21.9, \delta_{\mathrm{H}} 21.5$ and 2.20 in the ratio $\sim 2: 1$, respectively).
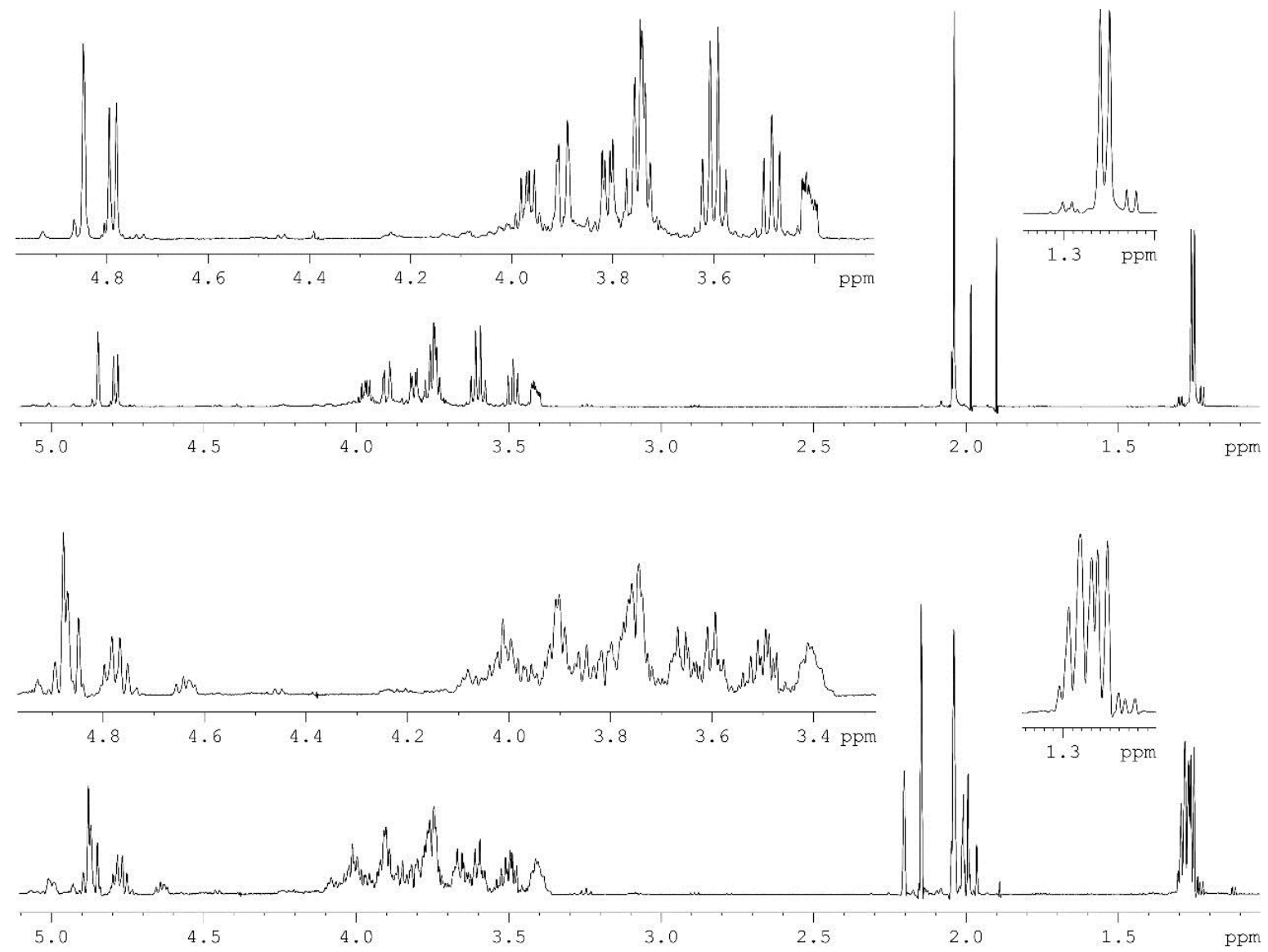

Figure 1. ${ }^{1} \mathrm{H}-\mathrm{NMR}$ spectra of the $O$-polysaccharide (bottom) and $O$-deacetylated polysaccharide (top) from A. hydrophila AH-1. 

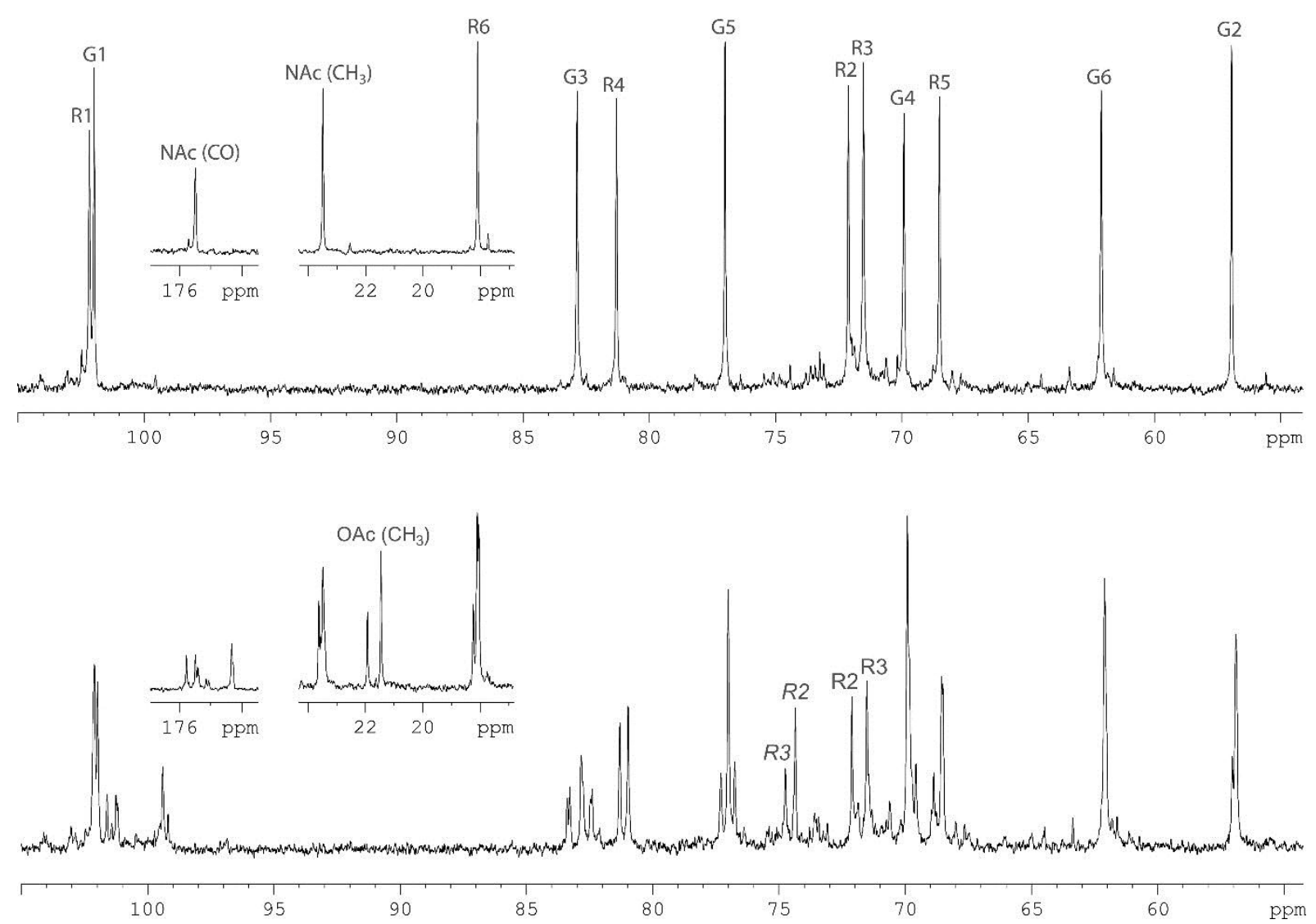

Figure 2. ${ }^{13} \mathrm{C}$-NMR spectra of the $O$-polysaccharide (bottom) and $O$-deacetylated polysaccharide (top) from A. hydrophila AH-1. Numbers refer to carbons in the GlcNAc and Rha residues denoted as $\mathrm{G}$, and R, respectively. Peak annotations for the $O$-acetylated Rha residues are italicized.

Indeed, spectra of the $O$-deacetylated polysaccharide (DPS) (Figures 1 and 2, top) were typical of a regular polymer. They showed signals for two anomeric atoms at $\delta_{\mathrm{H}} 4.78$ and 4.84, $\delta_{\mathrm{C}} 102.0$ and 102.2, one $\mathrm{CH}_{3}-\mathrm{C}$ group (C6 of Rha) at $\delta_{\mathrm{H}} 1.26, \delta_{\mathrm{C}} 18.1$, one $\mathrm{HOCH}_{2}-\mathrm{C}$ group (C6 of GlcNAc) at $\delta_{\mathrm{C}} 62.1$, one nitrogen-bearing carbon ( $\mathrm{C} 2$ of GlcNAc) at $\delta_{\mathrm{C}} 56.9$, other sugar protons at $\delta_{\mathrm{H}} 3.42-3.97$ and carbons at $\delta_{\mathrm{C}} 68.5-82.9$ as well as one $N$-acetyl group at $\delta_{\mathrm{H}} 2.04, \delta_{\mathrm{C}} 23.5\left(\mathrm{CH}_{3}\right)$ and $175.5(\mathrm{CO})$.

The NMR spectra of the DPS were assigned (Table 1) and the following structure of the disaccharide repeating unit of the DPS was established using two-dimensional NMR techniques essentially as described [17]: $\rightarrow 4)-\alpha-L-R h a p-(1 \rightarrow 3)-\beta-D-G l c p N A c-(1 \rightarrow$.

Table 1. ${ }^{1} \mathrm{H}-\mathrm{NMR}$ and ${ }^{13} \mathrm{C}$-NMR chemical shifts $(\delta$, ppm) of the $O$-deacetylated polysaccharide (DPS) from A. hydrophila AH-1.

\begin{tabular}{cccccccc}
\hline Sugar Residue & Nucleus & $\mathbf{1}$ & $\mathbf{2}$ & $\mathbf{3}$ & $\mathbf{4}$ & $\mathbf{5}$ & $\mathbf{6}(\mathbf{6 a}, \mathbf{6 b})$ \\
\hline \multirow{2}{*}{$\rightarrow 3)-\beta-\mathrm{D}-$ Glc $p$ NAc- $(1 \rightarrow$} & ${ }^{1} \mathrm{H}$ & 4.78 & 3.76 & 3.61 & 3.49 & 3.42 & $3.74,3.90$ \\
& ${ }^{13} \mathrm{C}$ & 102.0 & 56.9 & 82.9 & 69.9 & 77.0 & 62.1 \\
\hline \multirow{2}{*}{$\rightarrow 4)-\alpha-L-R h a p-(1 \rightarrow$} & ${ }^{1} \mathrm{H}$ & 4.84 & 3.74 & 3.81 & 3.60 & 3.97 & 1.26 \\
& ${ }^{13} \mathrm{C}$ & 102.2 & 72.1 & 71.5 & 81.3 & 68.5 & 18.1 \\
\hline
\end{tabular}


A comparison of the two-dimensional ${ }^{1} \mathrm{H},{ }^{13} \mathrm{C}$ heteronuclear single-quantum coherence (HSQC) spectra of the two polysaccharides revealed down-field displacements in both dimensions of parts of the Rha $\mathrm{H} 2 / \mathrm{C} 2$ and $\mathrm{H} 3 / \mathrm{C} 3$ cross-peaks from their positions in the spectrum of the DPS at $\delta_{\mathrm{H}} / \delta_{\mathrm{C}}$ $3.74 / 72.1$ and $3.81 / 71.5$ to $\delta_{\mathrm{H}} / \delta_{\mathrm{C}} 4.87 / 74.4$ and 5.00/74.8, respectively, in the spectrum of the $O$-polysaccharide. These displacements were evidently due to a deshielding effect of the $O$-acetyl group and indicated partial $O$-acetylation of the Rha residue at position 2 or 3 . As judged by relative intensities of the signals for non-acetylated and $O$-acetylated Rha residues as well as $\mathrm{CH}_{3}$ signals of Rha, $N$-acetyl and $O$-acetyl groups, the degree of $O$-acetylation at positions 2 and 3 is $40 \%$ and $20 \%$, respectively.

Therefore, the $O$-polysaccharide structure of $A$. hydrophila AH-1 (O11) may be depicted as follows:

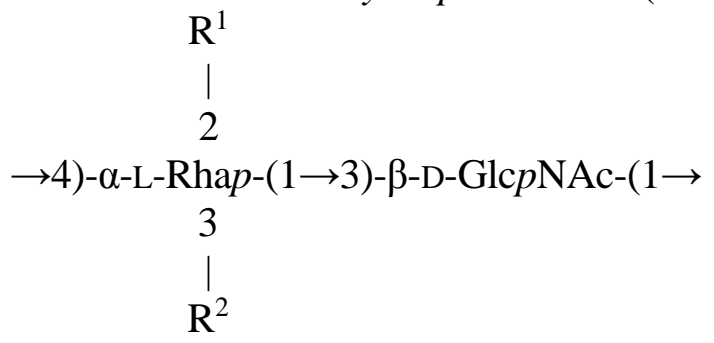

Variant I ( 40\%): $\mathrm{R}^{1}=\mathrm{R}^{2}=\mathrm{H}$ (non- $O$-acetylated form)

Variant II ( 40\%): $\mathrm{R}^{1}=\mathrm{Ac}, \mathrm{R}^{2}=\mathrm{H}$ (major mono- $O$-acetylated form)

Variant III ( 20\%): $\mathrm{R}^{1}=\mathrm{H}, \mathrm{R}^{2}=\mathrm{Ac}$ (minor mono- $O$-acetylated form)

The structure established resembles the reported $O$-polysaccharide structure of another $A$. hydrophila strain studied (SJ-44 from the collection of the Northwest Atlantic Fisheries Centre, St. John's, Newfoundland, Canada) [14], which differs in a lower degree of $O$-acetylation (21\% at position 2 of Rha and no $O$-acetyl group at position 3). Recently, and $O$-polysaccharide resembling the same structure from $A$. sobria strain Pt312 with a different degree of $O$-acetylation have been reported [18].

\subsection{O11-Antigen LPS Biosynthesis Gene Cluster (wbo11)}

A cosmid-based genomic library of A. hydrophila AH-1 (serotype O11) was constructed and introduced into E. coli DH5 $\alpha$ as previously described for other Aeromonas strains [19]. Because we previously detected that Aeromonas O11-antigen LPS contains rhamnose, we decided to construct DNA probes from $A$. hydrophila strain AH-3 rmlA and $B$ genes (two biosynthetic rhamnose genes, [20]). We screened the A. hydrophila AH-1 genomic library by colony Southern blot using these two DNA probes and found several tetracycline-resistant clones able to cross react with both probes. In order to identify the A. hydrophila AH-1 genes involved in the LPS O11-antigen biosynthesis, the complete nucleotide sequence of some positives recombinant clones was determined by using oligonucleotides complementary to cosmid pLA2917 [19] sequences flanking the DNA inserted. Other sequence-derived oligonucleotides were purchased (Amersham-Pharmacia Biotech) and used to complete the nucleotide sequence (GenBank KP856714). Analysis of the sequenced regions showed 22 complete putative open reading frames (ORFs) transcribed in the same direction, being nine of them (ORF1 to 4 and ORF17 to 21) genes involved in the O11-antigen LPS biosynthesis ( $w b$ cluster) as indicated in Figure 3 (in orange). 

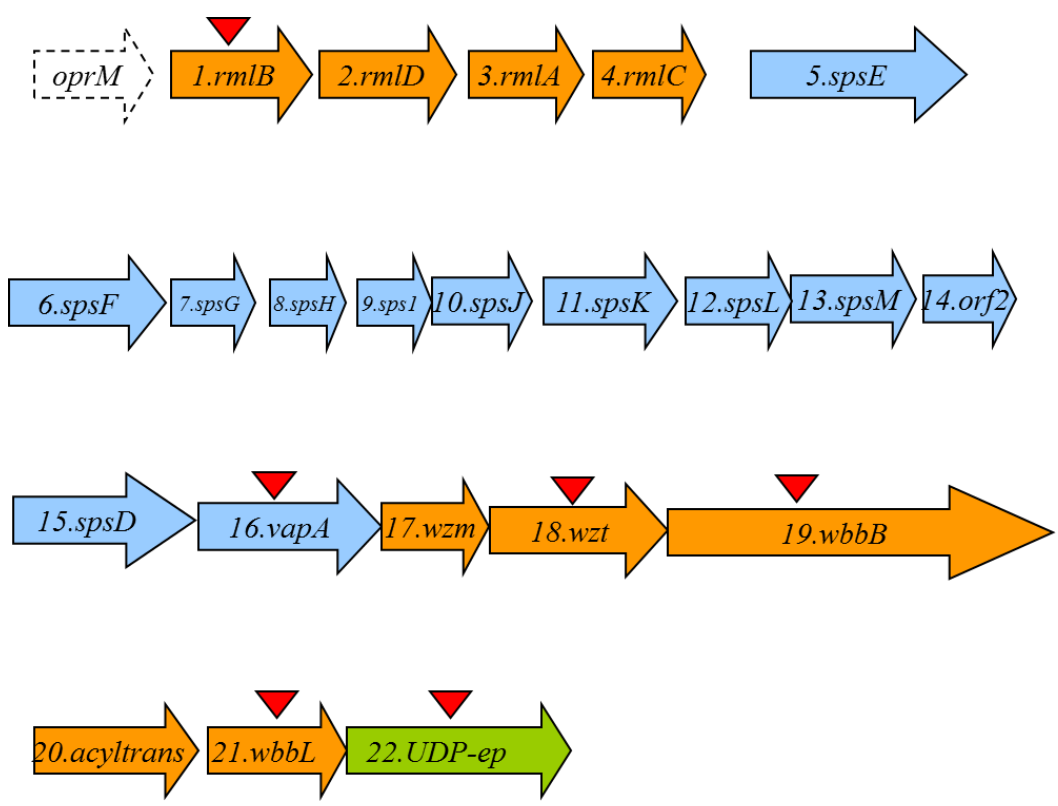

Figure 3. The A. hydrophila O11-antigen LPS $(w b)$ in orange and S-layer cluster in blue open reading frames (Orfs) detected as complete genes. The genes, numbered according to the ORF number, were named according to their similarity found by their encoding proteins with proteins of well characterized functions. The UDP-ep gene (in green) does not belong to any of both clusters. The oprM gene is incompletely sequenced and should be noticed that is also adjacent to the $w b$ O34-antigen LPS from strain AH-3 previously characterized [20]. Triangles indicated the in frame mutants obtained.

Computer analysis of the $w b$ gene cluster sequence revealed a conserved JUMPstart sequence with the 8 bp ops (operon polarity suppressor) sequence (GGCGGTAG) 132 bp upstream from the ORF1. The ops sequence is recognized by the bacterial antiterminator $\mathrm{RfaH}$, which can be recruited by the transcription elongation complex to reduce pausing and termination at intergenic sites of polycistronic operons, allowing RNA polymerase to conclude transcription of the distal genes in large operons [21,22].

However, we found several ORFs (5-16) between the genes involved in the LPS biosynthesis that belongs to a type II secretion system (T2SS) and the structural gene vapA (ORF16) that corresponds to the surface S-layer protein. These genes are indicated in blue in Figure 3. It seems clear that these ORFs are genes codifying for the production and export/assembly of the S-layer characteristic from strain AH-1. It is interesting to indicate that the point of insertion of the S-layer genes seems to be a truncated gene codifying for a putative Wzm protein that could be found just upstream of the S-layer genes. Downstream of the S-layer genes it could be observed complete ORFs encoding for Wzm and Wzt proteins characteristics of an ABC-2 type transporter. Finally, we found a gene (ORF22) labeled in green in Figure 3, codifying for a NAD-dependent dehydratase or UDP-sugar epimerase (UDP-ep) that initially seems not to belong to the $w b$ cluster, as described later, as their mutation do not abolish the O11-antigen LPS.

The corresponding analysis of the proteins encoded by these ORFs with their homology is presented in Table 2. All the homologies in Table 2 only included proteins with confirmed functions. 
Table 2. Characteristics of the A. hydrophila $O$-antigen LPS $(w b)$ and S-layer cluster ORFs.

\begin{tabular}{|c|c|c|c|c|c|}
\hline ORF & $\begin{array}{c}\text { Protein } \\
\text { Name }\end{array}$ & $\begin{array}{c}\text { Protein } \\
\text { Size } \\
\end{array}$ & Predicted Function & $\begin{array}{c}\text { Homologous Protein with } \\
\text { Known Function }\end{array}$ & $\begin{array}{c}\text { Percentage } \\
\text { Identity/Similarity }\end{array}$ \\
\hline \multicolumn{6}{|c|}{$O$-antigen LPS $(w b)$ cluster } \\
\hline 1 & $\mathrm{RmlB}$ & 361 & dTDP-glucose-4-6-dehydratase & RmlB multispecies Aeromonas & $100 / 100$ \\
\hline 2 & RmlD & 295 & dTDP-4-dehydro-rhamnose reductase & RmlD multispecies Aeromonas & $100 / 100$ \\
\hline 3 & $\mathrm{RmlA}$ & 292 & $\begin{array}{l}\text { Glucose-1-phosphate } \\
\text { thymildylyl transferase }\end{array}$ & RmlA multispecies Aeromonas & $100 / 100$ \\
\hline 4 & $\mathrm{RmlC}$ & 186 & $\begin{array}{l}\text { dTDP-4-dehydro-rhamnose } \\
\text { 3,5-epimerase }\end{array}$ & RmlC multispecies Aeromonas & $93 / 100$ \\
\hline \multicolumn{6}{|c|}{ Inserted S-layer protein cluster } \\
\hline 17 & Wzm & 272 & ABC-2 type transporter permease & Wzm multispecies Aeromonas & 98/99 \\
\hline 18 & Wzt & 438 & $\begin{array}{l}\text { ABC transporter ATP } \\
\text { binding protein }\end{array}$ & Wzt multispecies Aeromonas & $100 / 100$ \\
\hline 19 & WbbB & 1116 & $\mathrm{~N}$-acetyl glucosaminyl transferase & WbbB Klebsiella pneumonaie & $79 / 87$ \\
\hline 20 & acyltrans & 358 & Acyl transferase family 3 & $\begin{array}{c}\text { Acyltransferase Serratia } \\
\text { marcescens }\end{array}$ & $45 / 65$ \\
\hline 21 & WbbL & 268 & Rhamnosyl transferase & $\begin{array}{l}\text { Glucosyl transferase family } 2 \\
\text { A. veronii } \\
\text { Rhmanosyl transferase E. coli }\end{array}$ & $\begin{array}{c}100 / 100 \\
43 / 67\end{array}$ \\
\hline 22 & UDP-ep & 318 & $\begin{array}{l}\text { NAD-dependent dehydratase or } \\
\text { UDP-sugar epimerase }\end{array}$ & $\begin{array}{c}\text { NAD-dependent dehydratase or } \\
\text { UDP-sugar epimerase } \\
\text { multispecies Aeromonas }\end{array}$ & $100 / 100$ \\
\hline \multicolumn{6}{|c|}{ S-layer protein cluster } \\
\hline 5 & SpsE & 551 & S-layer secretion system protein $\mathrm{E}$ & $\begin{array}{l}\text { Type II secretion system (T2SS) } \\
\text { protein E A. hydrophila }\end{array}$ & $100 / 100$ \\
\hline 6 & $\mathrm{SpsF}$ & 399 & S-layer secretion system protein $F$ & $\begin{array}{c}\text { Type II secretion system(T2SS) } \\
\text { protein F A. hydrophila }\end{array}$ & $100 / 100$ \\
\hline 7 & SpsG & 144 & S-layer secretion system protein $G$ & $\begin{array}{c}\text { Type II secretion system (T2SS) } \\
\text { protein G A. hydrophila }\end{array}$ & $99 / 100$ \\
\hline 8 & SpsH & 123 & S-layer secretion system protein $\mathrm{H}$ & $\begin{array}{c}\text { Type II secretion system (T2SS) } \\
\text { protein H A. hydrophila }\end{array}$ & 98/99 \\
\hline 9 & SpsI & 139 & S-layer secretion system protein I & $\begin{array}{c}\text { Type II secretion system (T2SS) } \\
\text { protein I A. hydrophila }\end{array}$ & $99 / 100$ \\
\hline 10 & Sps $J$ & 201 & S-layer secretion system protein $\mathrm{J}$ & $\begin{array}{c}\text { Type II secretion system (T2SS) } \\
\text { protein J A. hydrophila }\end{array}$ & 98/99 \\
\hline 11 & SpsK & 340 & S-layer secretion system protein $\mathrm{K}$ & $\begin{array}{c}\text { Type II secretion system (T2SS) } \\
\text { protein K A. hydrophila }\end{array}$ & $100 / 100$ \\
\hline 12 & SpsL & 252 & S-layer secretion system protein $\mathrm{L}$ & $\begin{array}{c}\text { Type II secretion system (T2SS) } \\
\text { protein L A. hydrophila }\end{array}$ & $94 / 95$ \\
\hline 13 & SpsM & 198 & $\begin{array}{l}\text { Putative S-layer secretion system } \\
\text { protein M }\end{array}$ & $\begin{array}{l}\text { ORF1 hypothetical protein for } \\
\text { S-layer secretion A. hydrophila }\end{array}$ & $100 / 100$ \\
\hline 14 & Orf2 & 166 & $\begin{array}{l}\text { Putative S-layer hypothetical protein } \\
\text { secretion system }\end{array}$ & $\begin{array}{l}\text { ORF2 hypothetical protein for } \\
\text { S-layer secretion A. hydrophila }\end{array}$ & 98/99 \\
\hline 15 & SpsD & 743 & S-layer secretion system protein $\mathrm{D}$ & $\begin{array}{c}\text { Type II secretion system (T2SS) } \\
\text { protein D A. hydrophila }\end{array}$ & $100 / 100$ \\
\hline 16 & VapA & 469 & Surface layer protein & $\begin{array}{c}\text { Paracrystaline surface layer } \\
\text { protein } \\
\text { A. hydrophila }\end{array}$ & $100 / 100$ \\
\hline
\end{tabular}




\subsection{Mutant Isolation and Characterization}

As described in materials and methods section we obtained in frame mutants in ORFs 1, 16, 18, 19, 21, and 22 named AH-1 $\Delta$ rmlB, AH-1 $\Delta$ vapA, AH-1 $\Delta$ wzt, AH-1 $\Delta$ wbbB, AH-1 $\Delta$ wbbL, and AH-1 $\Delta$ UDP-ep, respectively. As it can be observed in Figure 4, mutants AH-1 $\Delta$ rmlB, AH-1 $\Delta$ wzt, AH-1 $\Delta$ wbbB, and AH-1 $\Delta$ wbbL were unable to produce $O$-antigen containing LPS when analyzed in a SDS-PAGE gel. However, AH-1 $\Delta$ vapA and AH-1 $\Delta$ UDP-ep mutants showed in the same gels identical LPS profile as the wild type strain with $O$-antigen ladder repetitions.

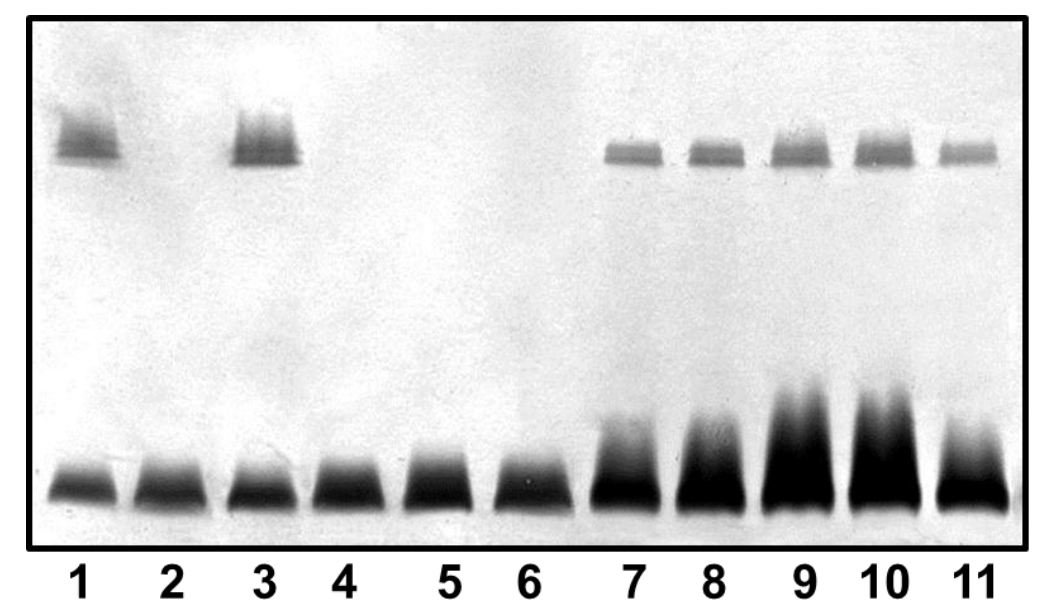

Figure 4. LPS analysed by SDS-PAGE (12\%) and silver stained from A. hydrophila AH-1

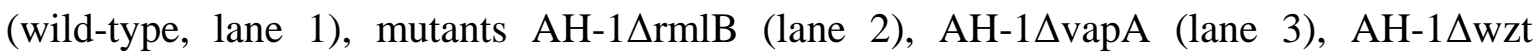
(lane 4), AH-1 $\Delta$ wbbB (lane 5), AH-1 $\Delta$ wbbL (lane 6), AH-1 $\Delta$ UDP-ep (lane 7), mutant AH-1 $\Delta$ rmlB complemented with AH-1 rmlB (lane 8), mutant AH-1 $\Delta$ wzt complemented with AH-1 wzt (lane 9), mutant AH-1 $\Delta$ wbbB complemented with AH-1 wbbB (lane 10), and mutant $\mathrm{AH}-1 \Delta \mathrm{wbbL}$ complemented with $\mathrm{AH}-1$ wbbL (lane 11).

We obtained outer-membrane proteins (OMp) and purified S-layer from mutant AH- $1 \Delta$ vapA as described in materials and methods. Analysis by SDS-PAGE gels showed the lack of a protein band of approximately $52 \mathrm{kDa}$ compared with the wild type (Figure 5A,B). This band reacts with specific serum anti-S protein in Western blot analysis (Figure 5C). No changes in OMp were observed for AH-1 $\Delta$ UDP-ep mutant.

The reintroduction of the corresponding wild type genes in $\mathrm{AH}-1 \Delta \mathrm{rmlB}, \mathrm{AH}-1 \Delta \mathrm{wzt}, \mathrm{AH}-1 \Delta \mathrm{wbbB}$, and $\mathrm{AH}-1 \Delta \mathrm{wbbL}$ fully restored the LPS profile of the wild type strain in silver-stained SDS gels. A similar situation was observed when wild-type vapA was reintroduced in mutant AH-1 $\Delta$ vapA, the presence in the OMp profile of the $52 \mathrm{kDa}$ protein reacting with specific serum anti-S protein was restored (Figures 4 and 5).

By colony Southern blot using DNA probes from the three chromosomal regions of waa from A. hydrophila strain AH-3 (wahA for region 1, waaE for region 2, and waaC for region 3 [15]), we screened the genomic library of $A$. hydrophila $\mathrm{AH}-1$, and we were able to found several tetracycline-resistant clones able to independently cross react with the different probes. The nucleotide sequence of the recombinant clones found for each region was determined in order to identify the A. hydrophila AH-1 genes conferring the LPS-core production. The complete nucleotide sequence was 
determined as previously indicated (GenBank KP856713). As it can be observed in Figure 6, region 1 containing seven ORFs and regions 2 and 3 consisting of 4 and 2 ORFs, respectively, showed the same organization as previously indicated for strain AH-3 [15].

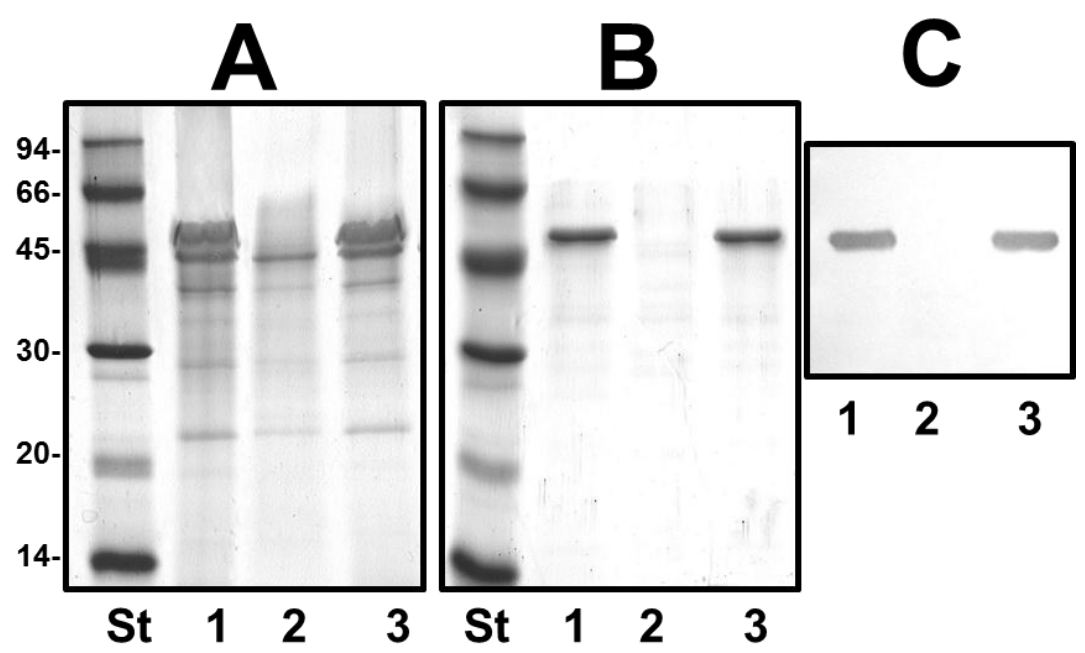

Figure 5. (A) Outer membrane proteins; (B) Isolated S-layer protein; and (C) Western blot using antiserum against S-layer protein of strains: AH-1 (wild type, lane 1), mutant AH-1 $\Delta$ vapA (lane 2), and AH-1 $\Delta$ vapA complemented with AH-1 vapA (lane 3). St, molecular weight standard.

The corresponding analysis of the proteins encoded by these ORFs from all regions renders more than $96 \%$ identity with the corresponding ones of strain AH-3. In order to confirm the gene identity of these three $\mathrm{AH}-1$ regions with the corresponding ones in strain $\mathrm{AH}-3$, we decided to complement three AH-3 LPS-core OS mutants (one from each region) with the corresponding AH-1 genes. Thus, AH-1 $w a h A, w a a F$, and waaC were independently introduced using plasmids constructed as described in materials and methods in $\mathrm{AH}-3 \Delta$ wahA, $\mathrm{AH}-3 \Delta$ waaF, and $\mathrm{AH}-3 \Delta$ waaC [15], respectively. The AH-3 $\Delta$ waaC and AH-3 $\Delta$ waaF mutants completely lack O34-antigen LPS and showed a faster migration of their R-form LPS in silver-stained SDS gels compared with the wild type strain. The AH-3 $\Delta$ wahA mutant showed a LPS producing mainly high molecular weight O34-antigen LPS and a faster migration of their R-form LPS in gels compared with the wild type strain. When the AH-1 wahA, waaF, and waaC were introduced to their respective AH-3 mutants, all of them recovered identical O34-antigen LPS profiles and R-form LPS migration in gels as their wild type strain AH-3 (serotype O34), as is shown in Figure 6 . No changes were observed when we introduced the plasmid vector alone.

The LPS isolated by the phenol-water procedure from the A. hydrophila AH-1 $\Delta \mathrm{rmlB}$ mutant (R-form LPS, as being unable to produce the $O$-antigen containing form but with a complete LPS core), was subjected to acetic acid reaction and submitted to GPC on Sephadex G-50 to render an OS mixture. This mixture showed molecular masses of 1696.8 and 1858.3 Da after ESIMS, as occurred with LPS-core of strain AH-3. GC of the alditol acetates derived after full acid hydrolysis revealed Gal, Glc, GlcN, D-glycero- and L-glycero-D-manno-heptose (D,DHep and L,DHep) in the ratios $0.4: 1: 1: 2.3: 4.2$, respectively. Again, this analysis was completely in agreement with the one performed for OS from strain AH-3 [23]. 


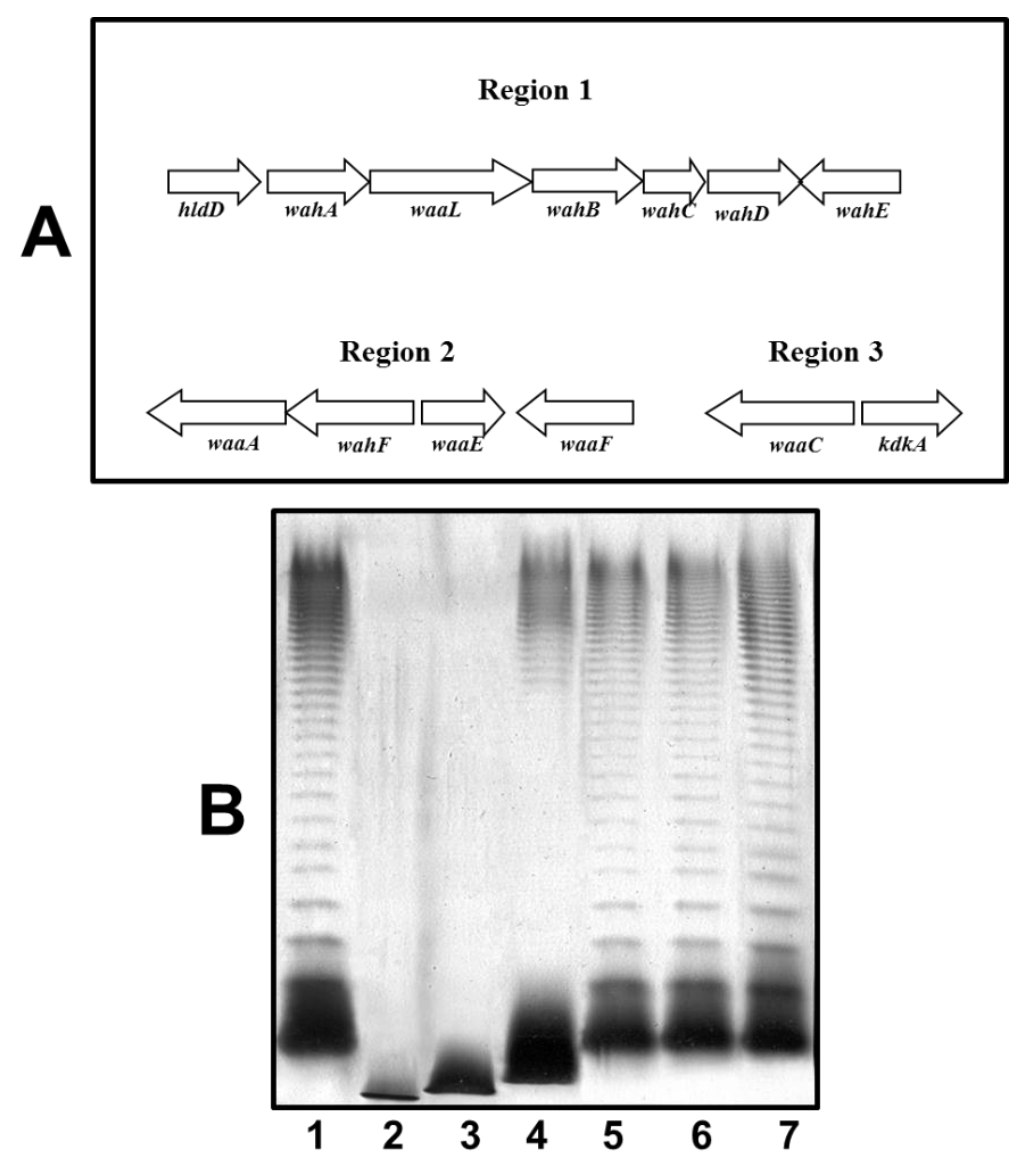

Figure 6. (A) Genetic organization of the A. hydrophila AH-1 three chromosomal regions containing genes for the LPS core biosynthesis. Transcription directions are indicated; (B) LPS analysed by SDS-PAGE (12\%) and silver stained from A. hydrophila AH-3 serotype O34

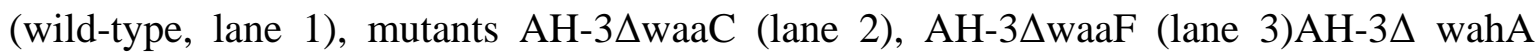
(lane 4), AH-3 $\Delta$ waaC complemented with AH-1waaC (lane 5), AH-3 $\Delta$ waaF complemented with $\mathrm{AH}-1$ waaF (lane 6), and AH-3 $\Delta$ wahA complemented with AH-1wahA (lane 7).

\section{Discussion}

The Aeromonas O11-antigen $w b$ gene cluster showed a $\% \mathrm{G}+\mathrm{C}$ of $48.4 \%$, lower than the $57 \%-65 \%$ expected for the species of the genus Aeromonas, characteristic of some $w b$ clusters that usually possess a $\mathrm{G}+\mathrm{C}$ content at least $10 \%$ below the species average. The encoded proteins are consistent with the chemical structure of the O11-antigen LPS: RmlBDAC (ORF1-4) for the production of rhamnose, and there was no need for specific biosynthetic genes for acetyl- $N$-glucosamine (GlcNAc), and the transferases WbbL (ORF21) (rhamnosyl transferase) and WbbB-like (ORF19) (GlcNAc transferase), respectively. The ORF19 (WbbB) protein showed high homology with proteins WbbA of the Serratia marcescens wbo4 [24] and WbbB of Klebsiella peumoniae wbo12 [25]. These proteins showed two domains: a capsule polysaccharide biosynthesis protein condensation domain over the first 125-275 amino acid residues, and a glycosyltransferase family 25 (LPS biosynthesis protein) domain characteristic of GlcNAc transferases which extends from the amino acid residue 500 to the end of the protein. The last domain shared a high homology with WbbA and B proteins while the first part of the protein shared high homology but decreased with the first domain of WbbA and B proteins. All these 
proteins were predicted to be anchored to the membrane, and WbbA and B have been suggested to be bifunctional, being the glycosyl transferase function in common. It seems clear that ORF19 (WbbB) protein could be another one of these proteins characteristic of $O$-antigen disaccharides biosynthesized by an ABC 2 transporter-dependent pathway. There is also one putative acetyl transferase (ORF20) which is in agreement with the acyl residues found in the O11-antigen LPS chemical structure.

ORF17 and 18 were similar to ABC-2 type transport system integral membrane and ATP-binding proteins, respectively (Table 2). Hydrophobicity analysis and identification of the putative transmembrane domains of the ORF17 protein, using the method of Klein et al. [26], suggest that it is an integral membrane protein. Also, the ORF18 protein showed the sequence GHNGAGKS (amino acid residues 76-83) which correspond to Walker box A, a motif present in ATP-binding proteins, as well as the ABC transporter family signature YSSGMYVRLAFAVQA (amino acid residues 148-162). Thus, ORF17 and 18 were named $w z m$ and $w z t$, respectively. Two main known pathways for $O$-antigen export have been established [27], the Wzy-dependent pathway for heteropolysaccharides structures and the ABC 2 transporter-dependent pathway mainly for homopolysaccharides or disaccharides. The presence of complete Wzm (ORF17) and Wzt (ORF18) showed that the O11-antigen LPS belongs to the second pathway. To synthesize $\mathrm{O}$ antigens, monomers are assembled on a lipid carrier (undecaprenol phosphate) by enzymes which can be or not encoded in the wbo11 gene cluster before their incorporation into the LPS molecule. In this case, we could not find such enzyme encoded by the $w b$ o11.

Accordingly with all these points, mutants $\mathrm{AH}-1 \Delta \mathrm{rmlB}, \mathrm{AH}-1 \Delta \mathrm{wzt}, \mathrm{AH}-1 \Delta \mathrm{wbbB}$, and $\mathrm{AH}-1 \Delta \mathrm{wbbL}$ were unable to produce $O$-antigen containing LPS when analyzed in an SDS-PAGE gel. However, AH-1 $\triangle$ UDP-ep mutant showed an identical LPS profile as the wild type strain with the presence of $O$-antigen ladder repetitions. For this reason, we decided that ORF22 (UDP-ep) deso not belong to the $w b 011$ and O11-antigen LPS biosynthesis is not necessary. However, we could not exclude the remote possibility that a functional homologue could be located in a different chromosomal location.

The genes for the biosynthesis and assembly of the S-layer are inserted in the middle of the $w b$ cluster (Figure 3 and Table 2). Also, the point of insertion seems to be a truncated gene codifying for a Wzm protein that could be found just upstream of the S-layer genes. Adjacent to this broken gene, it could be observed that the S-layer encoding genes included a large group of T2SS (ORF5 to 12 and ORF15) genes, plus some genes encoding hypothetical proteins related to this specific S-layer T2SS system (ORF13 and 14), and the final gene encoding the unique protein that forms the S-layer (vapA, ORF16) characteristic of the serotype O11 strains. Downstream to them, we found the complete genes encoding for Wzm and Wzt proteins (ORF17 and ORF18, as previously indicated). According to this, the AH-1 $\Delta$ vapA mutant showed identical LPS profile as the wild type strain with $O$-antigen ladder repetitions, but lacked the VapA protein being then unable to produce the S-layer.

When we inspected all the currently available Aeromonas genomes, we found only one that contained a copy of the vapA gene, the A. veronii $\mathrm{Hm} 21$ genome. Analysis of this genome shows that from ERF63505.1 to ERF63574.1, encoded products are equivalent to A. hydrophila AH-1 ORF1 to 22 , with genes for biosynthesis and assembly of the S-layer inserted in the middle of the $w b$ cluster. The point of insertion is also a truncated gene codifying for a Wzm protein. Furthermore, A. salmonicida is an important fish pathogen being its major virulence factor an S-layer (named A-layer), which mainly consists of a two-dimensional crystalline tetragonal proteinaceous (A-protein with a molecular weight of $49 \mathrm{KDa}$ ) array [28], tethered to the cell by the LPS [29]. The initial analysis of currently available 
genomes from this species also seems to indicate that they share the same situation as A. hydrophila AH-1 concerning the biosynthesis and assembly of the A-layer genes inserted in the middle of a putative $w b$ cluster.

Genetics data and preliminary chemical analysis indicated that the LPS-core for strain AH-1 is identical to the one for strain AH-3. The complementation studies using AH-1 waa genes with AH-3 LPS-core well defined mutants are in agreement with this identity.

\section{Materials and Methods}

\subsection{Bacterial Strains, Plasmids, and Growth Conditions}

The bacterial strains and plasmids used in this study are listed in Table 3. E. coli strains were grown on Luria-Bertani (LB) Miller broth and LB Miller agar at $37{ }^{\circ} \mathrm{C}$, while A. hydrophila strains were grown either in tryptic soy broth (TSB) or agar (TSA) at $30^{\circ} \mathrm{C}$. Ampicillin $\left(100 \mu \mathrm{g} \cdot \mathrm{mL}^{-1}\right)$, chloramphenicol $\left(20 \mu \mathrm{g} \cdot \mathrm{mL}^{-1}\right)$, and tetracycline $\left(25 \mu \mathrm{g} \cdot \mathrm{mL}^{-1}\right)$ were added to the different media when required.

Table 3. Bacterial strains and plasmids used.

\begin{tabular}{|c|c|c|}
\hline Strain or Plasmid & Relevant Characteristics & Reference or Source \\
\hline \multicolumn{3}{|c|}{ E. coli strains } \\
\hline DH5 $\alpha$ & $\mathrm{F}^{-}$end A hsdR17 ( $\left.\mathrm{rK}^{-} \mathrm{mK}^{+}\right)$supE44 thi-1 recA1 gyr-A96_80lacZM15 & [30] \\
\hline MC1061 & thi thr1 leu6 proA2 his4 argE2 lacY1 galK2 ara14 xyl5, supE44, $\lambda$ pir & [31] \\
\hline \multicolumn{3}{|c|}{ A. hydrophila strains } \\
\hline $\mathrm{AH}-1$ & O11, Wild type & [32] \\
\hline $\mathrm{AH}-1 \Delta \mathrm{rmlB}$ & AH-1 rmlB in frame mutant unable to produce O11-antigen LPS & This study \\
\hline $\mathrm{AH}-1 \Delta \mathrm{wzt}$ & AH-1 wzt in frame mutant unable to produce O11-antigen LPS & This study \\
\hline $\mathrm{AH}-1 \Delta \mathrm{wbbB}$ & $\mathrm{AH}-1 w b b B$ in frame mutant unable to produce O11-antigen LPS & This study \\
\hline $\mathrm{AH}-1 \Delta \mathrm{wbbL}$ & $\mathrm{AH}-1 w b b L$ in frame mutant unable to produce O11-antigen LPS & This study \\
\hline AH-1 $\Delta$ UDP-ep & AH-1 UDP-ep in frame mutant, able to produce O11-antigen LPS & This study \\
\hline AH-1 $\Delta$ vapA & $\begin{array}{l}\text { AH-1 vapA in frame mutant, unable to produce S-layer but able to } \\
\text { produce O11-antigen LPS }\end{array}$ & This study \\
\hline AH-3 3 wahA & AH-3 wahA LPS-core in frame mutant & [15] \\
\hline $\mathrm{AH}-3 \Delta \mathrm{waaF}$ & AH-3 waaF LPS-core in frame mutant & [15] \\
\hline $\mathrm{AH}-3 \Delta \mathrm{waaC}$ & AH-3 waaC LPS-core in frame mutant & [15] \\
\hline \multicolumn{3}{|c|}{ Plasmids } \\
\hline pGEMT easy & PCR generated DNA fragment cloning vector Amp ${ }^{R}$ & Promega \\
\hline pBAD33-Cm & Arabinose-inducible expression vector, $\mathrm{Cm}^{\mathrm{R}}$ & [33] \\
\hline pDM4 & Suicide plasmid, Sacarose, $\mathrm{Cm}^{\mathrm{R}}$ & [31] \\
\hline pLA2917 & Cosmid vector, $\mathrm{Km}^{\mathrm{R}}, \mathrm{Tc}^{\mathrm{R}}$ & [19] \\
\hline
\end{tabular}

${ }^{\mathrm{R}}$ resistant.

\subsection{General DNA Methods}

General DNA manipulations were done essentially as previously described [34]. DNA restriction endonucleases, T4 DNA ligase, E. coli DNA polymerase (Klenow fragment), and alkaline phosphatase were used as recommended by the Sigma-Aldrich (St Louis, MI, USA). 


\subsection{DNA Sequencing and Computer Analysis of Sequence Data}

Double-stranded DNA sequencing was performed by using the dideoxy-chain termination method [35] from PCR amplified DNA fragments with the ABI Prism dye terminator cycle sequencing kit (PerkinElmer, Barcelona, Spain). Oligonucleotides used for genomic DNA amplifications and DNA sequencing were purchased from Sigma-Aldrich (St Louis, MI, USA). Deduced amino acid sequences were compared with those of DNA translated in all six frames from nonredundant GenBank and EMBL databases by using the BLAST [36] network service at the National Center for Biotechnology Information and the European Biotechnology Information. ClustalW was used for multiple-sequence alignments [37].

\subsection{Mutant Construction}

The chromosomal in-frame AH- $1 \Delta \mathrm{rmlB}, \mathrm{AH}-1 \Delta \mathrm{vapA}, \mathrm{AH}-1 \Delta \mathrm{wzt}, \mathrm{AH}-1 \Delta \mathrm{wbbB}, \mathrm{AH}-1 \Delta \mathrm{wbbL}$, and AH-1 $\Delta$ UDP-ep deletion mutants were constructed by allelic exchange as described by Milton et al. [31]. Plasmids were transferred to A. hydrophila strains as previously indicated [20]. To complete the allelic exchange, the integrated suicide plasmid was forced to recombine out of the chromosome by growing on agar plates containing $10 \%$ sucrose. Mutants were selected based on surviving on plates containing $10 \%$ sucrose and loss of the chloramphenicol resistant marker of vector pDM4. The mutations were confirmed by sequencing of the whole constructs in amplified PCR products.

\subsection{Plasmid Constructions and Mutant Complementation Studies}

For complementation studies, the A. hydrophila AH-1 rmlB, vapA, wzt, wbbB, wbbL, wahA, waaF, and waaC genes were PCR amplified using appropriate oligonucleotides obtained from the sequenced clones and chromosomal AH-1 DNA as template, ligated to plasmid pGEMT (Promega), and transformed into E. coli DH5a. After checked, the corresponding genes were subcloned on plasmid pBAD33-Cm with an arabinose-inducible and glucose-repressible promoter [33]. Induction was obtained by adding L-arabinose to a final concentration of $0.2 \%(w / v)$. Plasmids were transferred to A. hydrophila strains as previously indicated [20].

\subsection{LPS Isolation and SDS-PAGE}

For screening purposes, LPS was obtained after proteinase K digestion of whole cells [37]. LPS samples were separated by sodium dodecyl sulfate-polyacrylamide gel electrophoresis (SDS-PAGE) and visualized by silver staining as previously described [38].

\subsection{Large-Scale Isolation of LPS Plus Isolation and O-Deacetylation of the O-Polysaccharide}

Cells (3 g dried weight) were digested with DNase, RNase ( $24 \mathrm{~h}, 3 \mathrm{mg}$ each) and Proteinase K (36 h, $3 \mathrm{mg}$ ) in $25 \mathrm{mM}$ Tris- $\mathrm{HCl}$ buffer $\mathrm{pH} 7.63$ containing $2 \mathrm{mM} \mathrm{CaCl}_{2}(30 \mathrm{~mL}$ ), the suspension was dialysed against distilled water and freeze-dried. Digested cells were extracted with aqueous $45 \%$ phenol at $68{ }^{\circ} \mathrm{C}$ [16], the extract was dialysed against tap water without separation of the layers, residual cells were removed by centrifugation, and the supernatant was freeze-dried to give 
lipopolysaccharide in a yield of $\sim 8 \%$. A lipopolysaccharide sample $(120 \mathrm{mg}$ ) was degraded with $0.1 \mathrm{M}$ sodium acetate buffer $\mathrm{pH} 4.2$ for $4 \mathrm{~h}$ at $100{ }^{\circ} \mathrm{C}$, the lipid precipitate was removed by centrifugation $(13,000 \times g, 20 \mathrm{~min})$, and a high-molecular-mass $O$-polysaccharide $(34 \mathrm{mg})$ was isolated from the supernatant by gel-permeation chromatography on a column $(50 \times 2.5 \mathrm{~cm})$ of Sephadex G-50 Superfine in pyridinium acetate buffer ( $4 \mathrm{~mL}$ pyridine and $10 \mathrm{~mL}$ HOAc in $1 \mathrm{~L}$ water) using a Knauer differential refractometer (Berlin, Germany) for monitoring. $O$-Deacetylation of the polysaccharide was performed by heating with aqueous $12 \%$ ammonia $(2 \mathrm{~mL})$ for $3 \mathrm{~h}$ at $60{ }^{\circ} \mathrm{C}$, ammonia was removed by stream of air, and the remaining solution was freeze-dried.

\subsection{Sugar Analysis and NMR Spectroscopy}

For sugar analysis, a polysaccharide sample $(0.5 \mathrm{mg})$ was hydrolyzed with $2 \mathrm{M} \mathrm{CF}_{3} \mathrm{CO}_{2} \mathrm{H}\left(100{ }^{\circ} \mathrm{C}\right.$, $4 \mathrm{~h}$ ), the monosaccharides were conventionally converted into the alditol acetates [39] and analyzed by GLC on a Varian 3700 chromatograph (Santa Clara, CA, USA) equipped with a fused-silica gel SPB-5 column using a temperature gradient from $150{ }^{\circ} \mathrm{C}(3 \mathrm{~min})$ to $320{ }^{\circ} \mathrm{C}$ at $5{ }^{\circ} \mathrm{C} \min ^{-1}$. The absolute configurations of the monosaccharides were determined as described [40], using the same GLC conditions as in sugar analysis.

NMR spectra were obtained on a Bruker DRX-600 spectrometer (Bremen, Germany) in 99.96\% $\mathrm{D}_{2} \mathrm{O}$ at $60{ }^{\circ} \mathrm{C}$ using internal acetone $\left(\delta_{\mathrm{H}} 2.225, \delta_{\mathrm{C}} 31.45\right)$ as calibration reference. Prior to the measurements, the samples were lyophilized twice from $99.9 \% \mathrm{D}_{2} \mathrm{O}$. Bruker XWINNMR 1.3 software was used to acquire and process the data. A mixing time of 100 and $200 \mathrm{~ms}$ was used in two-dimensional TOCSY and ROESY experiments, respectively.

\subsection{OM Protein and S-Layer Isolation and Characterization}

Outer membranes $(\mathrm{OM})$ were obtained by incubating membrane suspensions with $3 \%$ Sarkosyl in $20 \mathrm{mM}$ TrisHCl buffer ( $\mathrm{pH} \mathrm{8.0)}$ for $20 \mathrm{~min}$ at room temperature, as previously described [41]. The S-layer sheet material was obtained by using a modification of the procedure of Dooley and Trust [42]. Cells were grown overnight in $1000 \mathrm{~mL}$ of Luria Broth (LB) with agitation (200 rpm), harvested by centrifugation $(12,000 \times g, 20 \mathrm{~min})$, and washed twice in $20 \mathrm{mM}$ Tris- $\mathrm{HCl}(\mathrm{pH} 8.0)$. They were suspended in $100 \mathrm{~mL}$ of $0.2 \mathrm{M}$ glycine- $\mathrm{HCl}(\mathrm{pH} 2.8)$ and stirred at $4{ }^{\circ} \mathrm{C}$ for $30 \mathrm{~min}$. The cells were removed by a single centrifugation at $12,000 \times \mathrm{g}$ for $20 \mathrm{~min}$. The S-layer sheet material was collected by centrifugation at $40,000 \times g$ for $60 \mathrm{~min}$, suspended in $500 \mu \mathrm{L}$ of $20 \mathrm{mM}$ Tris- $\mathrm{HCl}$ (pH 8.0), and frozen at $-20^{\circ} \mathrm{C}$.

Protein were analysed by SDS-PAGE and separated protein bands were visualized by Coomassie Brilliant blue staining as previously described [41]. Anti-purified-S-layer antiserum was obtained and assayed as previously described [43]. After SDS-PAGE, immunobloting was carried out as previously described [44]. 


\section{Acknowledgments}

This work was supported by Plan Nacional de $\mathrm{I}+\mathrm{D}+\mathrm{i}$ grants (Ministerio de Economía y Competitividad, Spain), and Generalitat de Catalunya (Centre de Referència en Biotecnologia). We also thank Maite Polo for her technical assistance.

\section{Author Contributions}

All the authors contributed to experimental data, the analysis, and the writing of the paper.

\section{Conflicts of Interest}

The authors declare no conflict of interest.

\section{References}

1. Nazarenko, E.L.; Crawford, R.J.; Ivanova, E.P. The structural diversity of carbohydrate antigens of selected gram-negative marine bacteria. Mar. Drugs 2011, 9, 1914-1954.

2. List of Prokaryotic names with Standing in Nomenclature. Available online: http://www.bacterio.net (accessed on 9 April 2015).

3. MacDonell, M.T.; Swartz, D.G.; Ortiz-Conde, B.A.; Last, G.A.; Colwell, R.R. Ribosomal RNA phylogenies for the vibrio-enteric group of eubacteria. Microbiol. Sci. 1986, 3, 175-178.

4. Romanenko, L.A.; Schumann, P.; Zhukova, N.V.; Rohde, M.; Mikhailov, V.V.; Stackebrandt, E. Marinobacter bryozoorum sp. nov. and Marinobacter sediminum sp. nov., novel bacteria from the marine environment. Int. J. Syst. Evol. Microbiol. 2003, 53, 143-148.

5. Lin, Y.T.; Shieh, W.Y. Zobellella denitrificans gen. nov., sp. nov. and Zobellella taiwanensis sp. nov., denitrifying bacteria capable of fermentative metabolism. Int. J. Syst. Evol. Microbiol. 2006, $56,1209-1215$.

6. Martin-Carnahan, A; Joseph, S.W. Order XII. Aeromonadales. In Bergey's Manual of Systematic Bacteriology, 2nd ed.; Brenner, D.J., Krieg, N.R., Staley, J.T., Eds.; Springer: New York, NY, USA, 2005; Volume 2, PartB II, pp. 556-597.

7. Sakazaki, R.; Shimada, T. O-serogrouping scheme for mesophilic Aeromonas strains. Jpn. J. Med. Sci. Biol. 1984, 37, 247-255.

8. Thomas, L.V.; Gross, R.J.; Cheasty, T.; Rowe, B. Extended serogrouping scheme for motile, mesophilic Aeromonas species. J. Clin. Microbiol. 1990, 28, 980-984.

9. Miñana-Galbis, D.; Farfán, M.; Lorén, J.G.; Fusté, M.C. The reference strain Aeromonas hydrophila CIP 57.50 should be reclassified as Aeromonas salmonicida CIP 57.50. Int. J. Syst. Evol. Microbiol. 2010, 60, 715-717.

10. Kozińska, A.; Pękala, A. Characteristics of disease spectrum in relation to species, serogroups, and adhesion ability of motile aeromonads in fish. Sci. World J. 2012, doi:10.1100/2012/949358.

11. Janda, J.M.; Abbott, S.L. The genus Aeromonas: Taxonomy, pathogenicity, and infection. Clin. Microbiol. Rev. 2010, 23, 35-73. 
12. Janda, J.M.; Abbott, S.L.; Khashe, S.; Kellogg, G.H.; Shimada, T. Further studies on biochemical characteristics and serologic properties of the genus Aeromonas. J. Clin. Microbiol. 1996, 34, 1930-1933.

13. Dooley, J.S.; Lallier, R.; Shaw, D.H.; Trust, T.J. Electrophoretic and immunochemical analyses of the lipopolysaccharides from various strains of Aeromonas hydrophila. J. Bacteriol. 1985, 164, 263-269.

14. Shaw, D.H.; Squires, M.J. O-antigen structure in a virulent strain of Aeromonas hydrophila. FEMS Microbiol. Lett. 1984, 24, 277-280.

15. Jimenez, N.; Canals, R.; Lacasta, A.; Kondakova, A.N.; Lindner, B.; Knirel, Y.A.; Merino, S.; Regué, M.; Tomás, J.M. Molecular analysis of three Aeromonas hydrophila AH-3 (serotype O34) lipopolysaccharide core biosynthesis gene clusters. J. Bacteriol. 2008, 190, 3176-3184.

16. Westphal, O.; Jann, K. Bacterial lipopolysaccharide extraction with phenol-water and further application of the procedure. Methods Carbohydr. Chem. 1965, 5, 83-89.

17. Duus, J.Ø.; Gotfredsen, C.H.; Bock, K. Carbohydrate structural determination by NMR spectroscopy: Modern methods and limitations. Chem. Rev. 2000, 100, 4589-4614.

18. Turska-Szewczuk, A.; Pietras, H.; Duda, K.A.; Kozinska, A.; Pekala, A.; Holst, O. Structure of the O-specific polysaccharide from the lipopolysaccharide of Aeromonas sobria strain Pt312. Carbohydr. Res. 2015, 403, 142-148.

19. Nogueras, M.M.; Merino, S.; Aguilar, A.; Benedí, V.J.; Tomás, J.M. Cloning, sequencing and role in serum susceptibility of porin II from mesophilic Aeromonas sp. Infect. Immun. 2000, 68, 1849-1854.

20. Jiménez, N.; Canals, R.; Saló, M.T.; Vilches, S.; Merino, S.; Tomás, J.M. The Aeromonas hydrophila $w b^{*} \mathrm{O} 34$ gene cluster: genetics and temperature regulation. J. Bacteriol. 2008, 190, 4198-4209.

21. Artsimovitch, I.; Landick, R. The transcriptional regulator RfaH stimulates RNA chain synthesis after recruitment to elongation complexes by the exposed nontemplate DNA strand. Cell 2002, 109, 193-203.

22. Bailey, M.J.; Hughes, C.; Koronakis, V. RfaH and the ops element, components of a novel system controlling bacterial transcription elongation. Mol. Microbiol. 1997, 26, 845-851.

23. Knirel, Y.A.; Vinogradov, E.; Jimenez, N.; Merino, S.; Tomás, J.M. Structural studies on the R-type lipopolysaccharide of Aeromonas hydrophila. Carbohydr. Res. 2004, 339, 787-793.

24. Saigi, F.; Climent, N.; Piqué, N.; Sanchez, C.; Merino, S.; Rubirés, X.; Aguilar, A.; Tomás, J.M.; Regué, M. Genetic analysis of the Serratia marcescens N28b O4 antigen gene cluster. J. Bacteriol. 1999, 181, 1883-1891.

25. Izquierdo, L.; Merino, S.; Regué, M.; Rodríguez, F.; Tomás, J.M. A Klebsiella pneumoniae $O$-antigen heteropolysaccharide (O12) requiring an ABC-2-trasnporter dependent pathway. J. Bacteriol. 2003, 185, 1634-1641.

26. Klein, P.; Kanehisa, M.; DeLisi, C. The detection and classification of membrane-spanning proteins. Biochim. Biophys. Acta 1985, 815, 468-476.

27. Aquilini, E.; Tomás, J.M. Lipopolysaccharides (Endotoxins). In Reference Module in Biomedical Sciences; Elsevier: Amsterdam, The Netherlands, 2015; in press.

28. Ishiguro, E.E.; Kay, W.W.; Ainsworth, T.; Chamberlain, J.B.; Buckley, J.T.; Trust, T.J. Loss of virulence during culture of Aeromonas salmonicida at high temperature. J. Bacteriol. 1981, 148, 393-400. 
29. Belland, R.J.; Trust, T.J. Synthesis, export, and assembly of Aeromonas salmonicida A-layer analysed by transposon mutagenesis. J. Bacteriol. 1985, 163, 877-881.

30. Hanahan, D. Studies on transformation of Escherichia coli with plasmids. J. Mol. Biol. 1983, 166, 557-580.

31. Milton, D.L.; O’Toole, R.; Horstedt, P.; Wolf-Watz, H. Flagellin A is essential for the virulence of Vibrio anguillarum. J. Bacteriol. 1996, 178, 1310-1319.

32. Yu, H.B.; Srinivasa Rao, P.S.; Lee, H.C.; Vilches, S.; Merino, S.; Tomás, J.M.; Leung, K.Y. A Type III secretion system is required for Aeromonas hydrophila AH-1 pathogenesis. Infect. Immun. 2004, 72, 1248-1256.

33. Guzman, L.M.; Belin, D.; Carson, M.J.; Beckwith, J. Tight regulation, modulation, and high-level expression by vectors containing the arabinose PBAD promoter. J. Bacteriol. 1995, 177, 4121-4130.

34. Sambrook, J.; Fritsch, E.F.; Maniatis, T. Molecular Cloning: A Laboratory Manual, 2nd ed.; Cold Spring Harbor Laboratory: Cold Spring Harbor, NY, USA, 1989.

35. Sanger, F.; Nicklen, S.; Coulson, A.R. DNA sequencing with chain-terminating inhibitors. Proc. Natl. Acad. Sci. USA 1977, 74, 5463-5467.

36. Altschul, S.F.; Madden, T.L.; Schäffer, A.A.; Zhang, J.; Zhang, Z.; Miller, W.; Lipman, D.J. Gapped BLAST and PSI-BLAST: A new generation of protein database search programs. Nucleic Acids Res. 1997, 25, 3389-3402.

37. Thompson, J.D.; Higgins, D.G.; Gibson, T.J. CLUSTAL W: Improving the sensitivity of progressive multiple sequence alignment through sequence weighting, position specific gap penalties and weight matrix choice. Nucleic Acids Res. 1994, 22, 4673-4680.

38. Hitchcock, P.J.; Brown, T.M. Morphological heterogeneity among Salmonella lipopolysaccharide chemotypes in silver-stained polyacrylamide gels. J. Bacteriol. 1983, 154, 269-277.

39. Sawardeker, J.S.; Sloneker, J.H.; Jeanes, A. Spectrophotometric determination of high molecular weight quaternary ammonium cations in polysaccharides. Anal. Chem. 1965, 37, 243-246.

40. Widmalm, G.; Leontein, K. Structural studies of the Escherichia coli O127 $O$-antigen polysaccharide. Carbohydr. Res. 1993, 247, 87-89.

41. Esteve, C.; Amaro, C.; Toranzo, A.E. O-serogrouping and surface components of Aeromonas hydrophila and Aeromonas jandaei pathogenic for eels. FEMS Microbiol. Lett. 1994, 117, 85-90.

42. Dooley, J.S.G.; Trust, T.J. Surface protein composition of Aeromonas hydrophila strains virulent for fish: Identification of a surface array protein. J. Bacteriol. 1988, 170, 499-506.

43. Merino, S.; Rubires, X.; Aguilar, A.; Albertí, S.; Hernández-Allés, S.; Benedí, V.J.; Tomás, J.M. Mesophilic Aeromonas sp. serogroup O:11 resistance to complement-mediated killing. Infect. Immun. 1996, 64, 5302-5309.

44. Merino, S.; Nogueras, M.M.; Aguilar, A.; Rubires, X.; Albertí, S.; Benedí, V.J.; Tomás, J.M. Activation of the complement classical pathway (C1q binding) by mesophilic Aeromonas outer membrane protein. Infect. Immun. 1998, 66, 3825-3831.

(C) 2015 by the authors; licensee MDPI, Basel, Switzerland. This article is an open access article distributed under the terms and conditions of the Creative Commons Attribution license (http://creativecommons.org/licenses/by/4.0/). 